\title{
sion \\ Solar Powered Eco-friendly Mini Fridge
}

\author{
${ }^{1}$ Supriya P. Jamble, ${ }^{2}$ Pooja P. Bachal, ${ }^{3}$ Nikita S. Barge, ${ }^{4}$ Borate S. P. \\ ${ }^{1,2,3,4}$ Dept (E\&TC) SVPM College of Engineering, Malegaon(Bk), Baramati
}

\begin{abstract}
With the increase in industrialization \& modernization the concentration of $\operatorname{co} 2$ is increasing day by day which is causing many health related as well as environmental problems. Health related problems such as skin cancer,cataract etc., and environmental problems such as flood, drought, landslide etc. This increase in concentration of co2 leads to depletion of ozone layer caused by the release of CFC's. The equipments which cause this effect may include refrigerators, AC'setc. This project mainly focuses on a solution to control this problem caused due to release of CFC's from refrigerators .

The paper is designed for implementation of solar fridge with temperature monitoringas well as controlling. This implementation uses solar panels for charging a Lead Acid Battery (12V, 1.2 Amp hrs), a peltier thermoelectric device which when connected to battery generates cooling effect on one side and heat is generated on the other side which is unwanted andis drawn off using a cooling fan of heat sink. - The temperature sensor LM35 senses the temperature and converts it into an electrical signal, which is applied to the inbuilt ADC of PIC18F4520. The analog signal is converted into digital format by the analog-to-digital converter(ADC). The temperature values sensed by LM35 are displayed on the 16x2-line LCD. The main advantage of this project is it is eco friendly as peltier effect is used as an alternative to compressor.
\end{abstract}

Keywords-PIC18F4520,peltierthermoelectric device,temperature sensor (LM35),Lead Acid Battery,analog2-to-digital converter (ADC).

\section{INTRODUCTION}

As we know that the global warming is being increasing year by year and the reasons for this increase may include pollution, deforestation, water contamination, etc...By keeping in mind this severe problem,we are designing a mini solar based refrigerator which is cheaper as well as eco-friendly.

Solar energy is emerged as a vital source of energy over the past two or three decades. As this is renewable source of energy which can be generated again and again it is widely used for a variety of industrial and domestic applications. Some systems based on a solar collector are designed to collect the sun's energy and to convert it into either electrical power or thermal energy.

Domestic cooling systems such as refrigerators, Ac's utilize a compressor and a working fluid to transfer heat. Thermal energy is absorbed and released as the working
Fluid undergoes expansion and compression and changes phase from liquid to vapor and back, respectively. Semiconductor thermoelectric coolers (peltier coolers) offer many advantages over domestic systems. They are entirely solid-state ,rugged ,reliable and quiet due to absence of moving parts. They use no ozone depleting agents like chlorofluorocarbons,offering a more environmentally responsible alternative to conventional refrigeration. They can be extremely compact, much more so than compressor-based systems.

Objective of this project is to design thermoelectric Refrigerator ,UtilizePeltier effect to refrigerate and maintain a specified temperature.

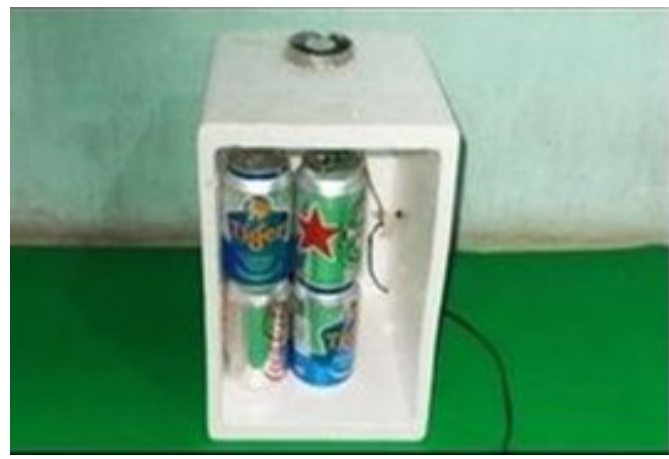

Fig1:Ecofriendlypeltier fridge.

II. BLOCK DIAGRAM

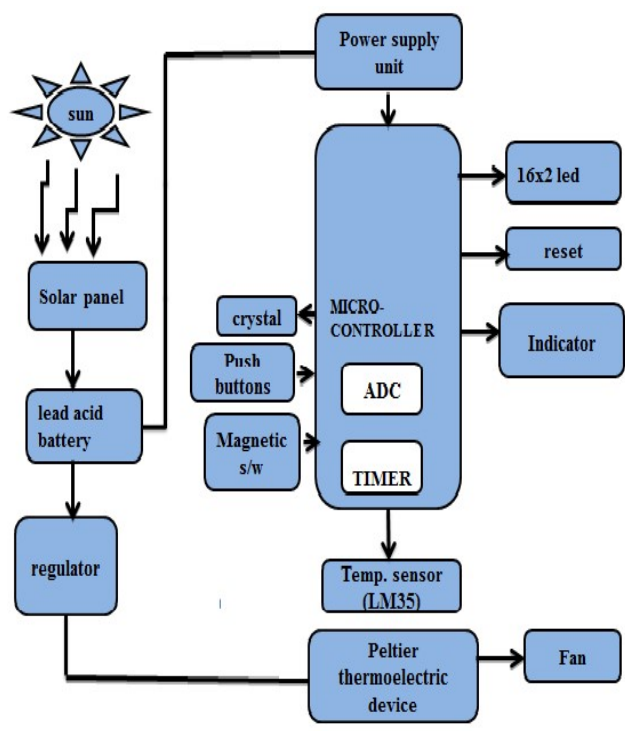

Fig2: Block diagram. 


\section{Solar panel:}

A solar panel is a device that absorbs the sun's energy in the form of photons, which are very small packets of electromagnetic radiation energy, and converts them into electrical current that can be used to power electrical loads.solar panels is a very conventional way to produce electricity for many applications. This energy is used further for charging the lead acid battery.

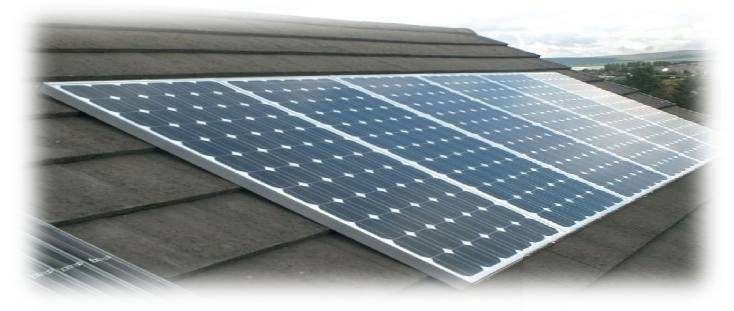

Fig3: Solar panel.

\section{Battery:}

Lead acid battery is used. The battery is charged by solar panel.It provides supply to overall circuit and also to thepeltier device which is connected externally.

\section{Temperature Sensors:}

The temperature sensor(LM35) senses the analog temperature generated by peltier device and provide it to the inbuilt ADC of PIC 18F4520.

\section{Magnetic Switch:}

This switch is used for door opening indication. Whenever the door is opened switch is open circuited and timerstarts.After the completion of specified time the buzzer gives the indication for the closing of door.

\section{Peltier Device:}

Peltier device is the main component of this implementation.In 1821, a germanscientist thomasseeback discovered Seebackeffect.Heput an experimental setup in which he connected two dissimilar metal end to end and observed that an Emfwas induced.Again in 1834,a frenchphysicst,JeanPeltier discovered Peltiereffect,which was exactly opposite to that of seeback effect.

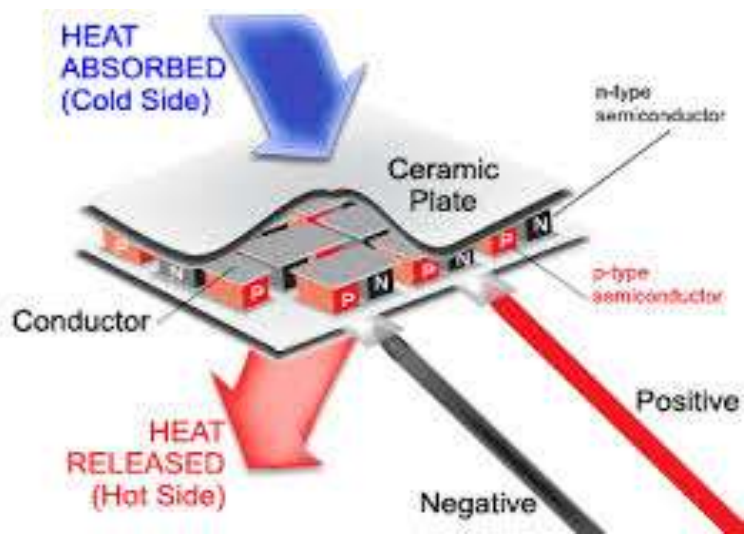

Fig4: Peltier device
For the discovery he also made the similar setup as that ofseeback,the only difference was he applied the voltage in between the metalsends. Due to which current start to flow and it was observed that one end was cooled and the other end was heated,the unwanted heat was drawn off using the fan of heat sink and the cooled temp was used for the refrigeration.this lead to the discovery of the peltier effect and hence the device.

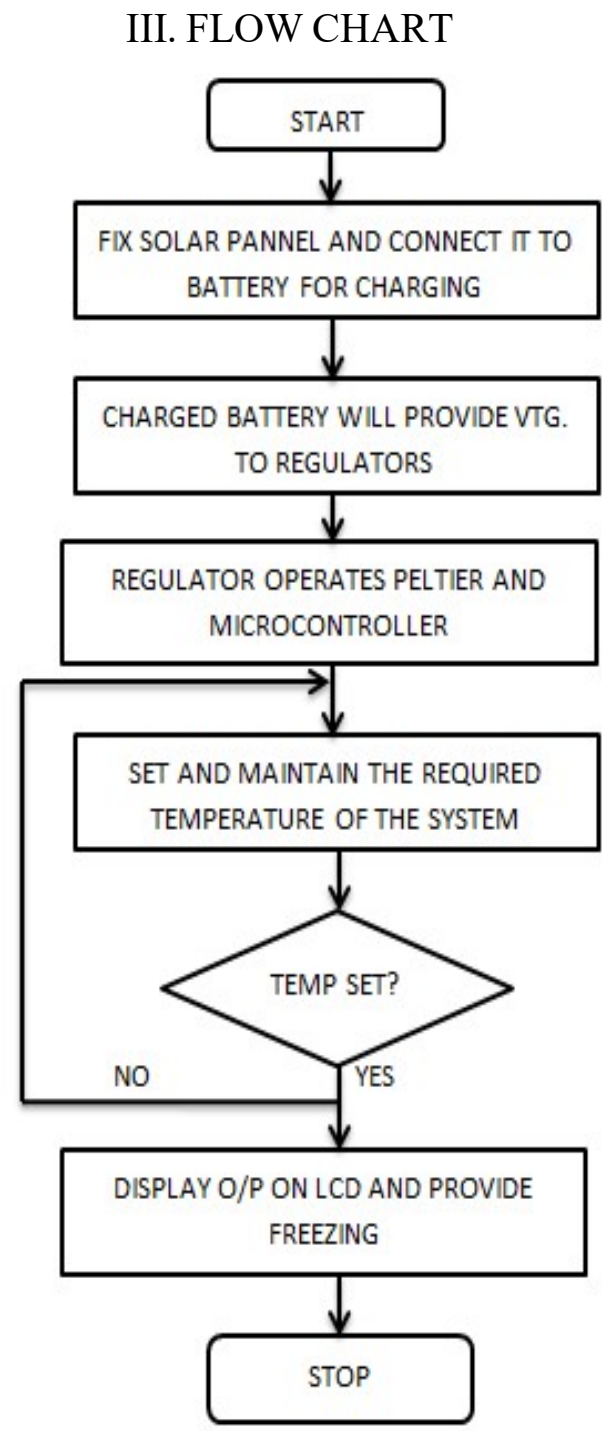

Fig5: Flow diagram

IV.ALGORITHM

\section{STEP 1:START}

- $\quad$ STEP 2:Solar panel absorbs heat in the form of photons \& charges the LAB.

- STEP 3:Voltage is given to voltage regulator $1 \& 2$.

- $\quad$ STEP4:Input temp provided by user through push buttons.

- $\quad$ STEP5:Peltier device energizes \& provides peltier effect. 
- $\quad$ STEP6:Close loop system forms \& temperature displayed on LCD.

- STEP7:As per temperature setting system provides cooling

\section{- STEP8:END.}

\section{V.FUTURE SCOPE}

Solar power nowadays is playing a major role in meetingthe energy requirement of our country.It is being developed at a very fast rate and its applications in many areas are being explored.The fridge is intended at exploring the same and provides

An efficient and economical solution to the areas where there is no electricity and cooling is required.

Though this fridge is working satisfactorily to its full capacity,still many changes and improvements can be done in this fridge to make it more users friendly and sophisticated in nature.this measures and changes, if implemented can play an important role in the future models to be developed. Some of these measures and changes are:

1. Number of peltier units can be increased to further decrease the temperature inside the fridge.

2. Same fridge can be used for heating purpose if we also insulate the other side i.e. heating side of the fridge within the box.

3. To increase the volume of the fridge maintaining the same temperature inside the fridge, number of peltier units and heat sink has to be increased.

4. This fridge can be made of the wodden material to make it more sturdy in constructions.wood will also act as an additional insulator for the cooling compartment.

5. This fridge can be installed in the four wheller at the time of manufacturing of vehicles.

\section{VI.APPLICATIONS}

\section{AT REMOTE PLACES:}

It can be used at backward and remote places where there is scarcity of electricity.

\section{IN RESTAURANTS/HOTELS:}

In restaurants/hotels for preservation of perishable items.

\section{LABORATORY:}

It can be used in laboratory, scientific instruments.

\section{MEDICINAL AND PHARMACEUTICAL EQUIPMENT:}

Medicines and injections needed at the primary health care centre's in the villages where there is sporadic or no power supply.

\section{CONCLUSION}

This project's main objective is to develop a mini compressor less solar fridge. The application of this fridge is very wide and it can be used in various places for variety of operation. Also the main purpose for which this fridge is made is being fulfilled as the space inside the fridge is sufficient enough to cool appropriate amount of stuffs, such as medicines and injections needed at the primary health care centers in the villages where there is scarcity of power supply.

\section{REFERENCES}

[1] B.Shreekar\&M.Vedachary, Implementation of solar fridge with fast chilling application with temperature monitoring using LPC2148.International Journal Of Advanced Research and Innovation Vol. II, Issue .1 2013.

[2] Angalaanilkumar\&K.Venkatesswarlu Implementation of solar fridge with fast chilling applications.InternationalJournal\& Magazine of Engineering, Technology, ManagementandResearch.Vol.no2, 2015.

[3] MayankAwasthi\& K V Mali,Design and Development of thermoelectric refrigerator.International journal of mechanical engineering \& robotics research,Vol.1ISSN2278 - 0149 Vol. 1, 2012.Vol.no.2, 2015.

[4] Design and development of thermoelectric refrigerator.International journal ofmechanical engineering \& robotics research,Vol.1ISSN2278 - 0149 Vol. 1,2012.Vol.no.2,2015.Dr. Essam Eilbadri Abukhder/ International Journal of Engineering \& Science Research IJESR/June 2014/ Vol 4/Issue 6/473 479.

[5] Abdul-Wahab SA, Elkamel A, Al-Damkhi AM, Al - Habsi IA, Al - Rubaiey H, Al - Battashi A, Al -Tamimi A, AlMamari K, Chutani M. Omani Bedouins' readiness to accept solar thermoelectric refrigeration systems. International J.Energy Technology and Policy 2009; 7: 127-136.

[6] Dai YJ, Wang RZ, Ni L. Expr. Investigation on A Thermo- Electric Refrigerator Driven By Solar Cells. Renew Energy 2003; 28: 949-59.

[7] Christian J L and Jadar R Barbosa Jr (2011), "Thermodynamic Comparison of Peltier, Stirling, and Vapor Compression Portable Coolers", Applied Energy, Vol. 9, pp.51-5.

[8] Astrain D and Vian J G (2005), “Computational Model for Refrigerators Based on Peltier Effect Application", Applied Thermal Engineering, Vol. 25, No. 13, pp. 3149-3162. 